\title{
Gruppenreligionen im römischen Reich
}

Sozialformen, Grenzziehungen und Leistungen

Hrsg. v. Jörg Rüpke

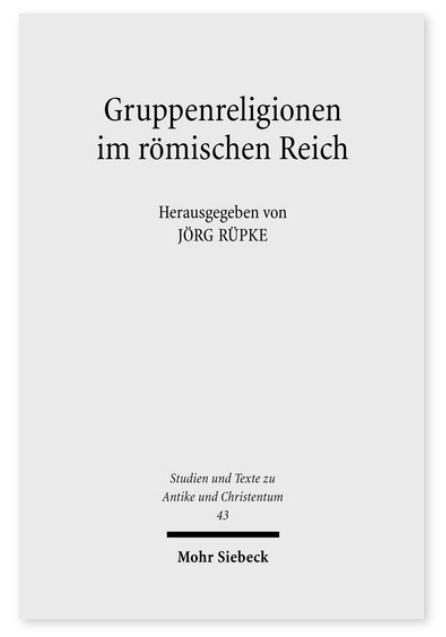

2007. VII, 212 Seiten. STAC 43

ISBN 978-3-16-151342-8 DOI 10.1628/978-3-16-151342-8 eBook PDF 64,00€

ISBN 978-3-16-149128-3

fadengeheftete Broschur $64,00 €$
Die Autoren der Beiträge in diesem Band, der aus einem Kolloquium des Schwerpunktprogramm »Römische Reichs- und Provinzialreligion« erwachsen ist, konzentrieren sich auf eine besondere Sozialform von Religion, nämlich auf Religionen, die sich über das Prinzip der Mitgliedschaft oder »Einweihung« als dauerhafte Kultgruppen organisieren. Im Mittelpunkt stehen Fragen nach der internen Strukturierung und der kultischen Intensivierung: Wie werden die Sozialbeziehungen in religiösen Gruppen strukturiert, strukturieren Mitgliedschaften und Einweihungen religiöse Biographien? Welche Rolle spielen Kulträume einerseits, die Frequenz von Kultakten und gemeinsamen Banketten andererseits? Dabei richtet sich der Blick auf das Verhältnis von Gruppenreligionen zu anderen traditionellen, öffentlichen oder krisenorientierten Kulten in lokalen Kontexten. Es wird deutlich, wie stark die scheinbar exklusiven religiösen Gruppierungen in lokale Religion integriert sind und zugleich auf der Basis geteilter Annahmen das kultische wie theologische Spektrum vergrößern. Ein wichtiges Ergebnis gegenüber der jüngeren Forschung zu religiösen Vereinen ist, daß der Organisationsgrad viel wechselhafter war, oft auch niedriger, die Lebensdauer der religiöse Gruppen viel kürzer, als unterstellt. Das Spektrum begann bei Kulten von Familien und Haussklaven; »Dachorganisationen«, die örtliche Gruppen zusammenfassten, kamen nur selten und nicht immer dauerhaft zustande.

Inhaltsübersicht

Inhalt:

Hubert Cancik: Haus, Schule, Gemeinde. Zur Organisation von fremden Religionen in Rom (1.-3.Jh.n.Chr.) - Andreas Bendlin: Die Konstruktion zivilen Ungehorsams. Religiöse Gruppenbildung im sogenannten Senatus Consultum de Bacanalibus und bei Livius 39,8-19 - Celia Schultz: Soziale Klassifikation und die religiöse Erfahrung von Frauen in der römischen Republik James D. G. Dunn: Boundary markers in early Christianity - Michael Bachmann: Zur Rezeptions- und Traditionsgeschichte des Paulinischen Ausdrucks »Erga nomou« - Johannes Woyke: Depontenzierung und Tabuisierung von Göttern nach 1 Ko 10 Jörg Rüpke: Integrationsgeschichten. Gruppenreligionen in Rom: Priester - Wolfgang Spickermann: Die Integration von Mysterienkulten in das lokale Pantheon in Gallien und Germanien - Alfred Schäfer: Dionysische Kultlokale in Kleinasien und dem Donauraum - Günther Schörner: Saturnkult als Gruppenreligion in der Africa proconsularis

Jörg Rüpke Born 1962; permanent fellow in Religious Studies at the Max Weber Centre for Advanced Cultural and Social Studies at the University of Erfurt and co-director of the International research group »Religion and Urbanity: Reciprocal Formations."

https://orcid.org/0000-0002-4173-9587

Jetzt bestellen:

https://mohrsiebeck.com/buch/gruppenreligionen-im-roemischen-reich-9783161513428?no cache=1

order@mohrsiebeck.com

Telefon: +49 (0)7071-923-17

Telefax: +49 (0)7071-51104 